\title{
The Nature of Hyperthermia in Neuroleptic Malignant Syndrome and the Use of Bromocriptine
}

\author{
P. Ken Gillman
}

Published online: 2 April 2010

(C) American College of Medical Toxicology 2010

The interesting and valuable case report of Morris et al. [1] invites further observations and speculations about this still mysterious syndrome: we do not know if NMS involves an abnormal degree of heat generation (and if so from where), or if there is a failure of heat dissipation. It is not even clear that NMS is a primarily hyperthermic/hypermetabolic syndrome, although psychiatrists certainly seem to think it is. Many reviews assume that, without discussion, or the presentation of direct evidence. This report supports the idea it may not be.

The term hyperthermia is not usually precisely defined: elevated temperature is not injurious until it reaches $\sim 39.5$ $40^{\circ} \mathrm{C}$, and the physiological range extends up to $39^{\circ} \mathrm{C}$ during normal activities [2]. Most patients with diagnosed 'NMS' do not develop a temperature exceeding $39^{\circ} \mathrm{C}$ even with only conservative treatment $[3,4]$. Therefore, NMS is a misleading term: it is hardly justified to call the syndrome malignant (and it is clearly much less malignant than $\mathrm{MH}$ by an order of magnitude), it occurs frequently without dopamine antagonist drugs of any sort [5], and it is often not, by any meaningful definition, hyperthermic.

This report is especially interesting because it documents the deterioration of the mental and neurological state in the absence of significant hyperthermia (maximum $39^{\circ} \mathrm{C}$ ), and it shows how changes unrelated to hyperthermia become life-threatening early in the development of the syndrome. If only we knew if this particular patient's brain temperature was $39^{\circ} \mathrm{C}$, or more, or less?

P. K. Gillman $(\bowtie)$

PO Box 86, 4750 Bucasia, Queensland, Australia

e-mail: kg@matilda.net.au
The usefulness of bromocriptine is unclear, and in this case seemingly of no benefit, despite early initiation. Bromocriptine is not only a dopamine agonist but also a serotonin 5-HT2A agonist [6]. This property promotes hyperthermia because 5-HT2A receptor activation mediates hyperthermia in serotonin toxicity and worsens the outcome in other models of hyperthermia like $\mathrm{MH}$ and heatstroke [7]: conversely, 2A antagonism improves such states. A DA agonist that is also a 5-HT2A antagonist, like apomorphine [8], may be preferable, the theoretical rationale being that D2 agonism promotes heat loss [9], and this has been reported as an efficacious strategy in the NMS-like condition Parkinsonism-hyperpyrexia syndrome [10].

\section{References}

1. Morris E, Green D, Graudins A (2009) Neuroleptic malignant syndrome developing after acute overdose with olanzapine and chlorpromazine. J Med Toxicol 5(1):24-6

2. Bouwknecht JA, Olivier B, Paylor RE (2007) The stress-induced hyperthermia paradigm as a physiological animal model for anxiety: a review of pharmacological and genetic studies in the mouse. Neurosci Biobehav Rev 31(1):41-59

3. Spivak B et al (2000) Frequency of neuroleptic malignant syndrome in a large psychiatric hospital in Moscow. Eur Psychiatry $15(5): 330-3$

4. Lee JW (2007) Catatonic variants, hyperthermic extrapyramidal reactions, and subtypes of neuroleptic malignant syndrome. Ann Clin Psychiatry 19(1):9-16

5. Thomas A, Onofrj M (2005) Akinetic crisis, acute akinesia, neuroleptic malignant-like syndrome, Parkinsonism-hyperpyrexia syndrome, and malignant syndrome are the same entity and are often independent of treatment withdrawal. Mov Disord 20(12):1671 (1 page only)

6. Cussac D et al (2008) Agonist-directed trafficking of signalling at serotonin 5-HT2A, 5-HT2B and 5-HT2C-VSV receptors mediated $\mathrm{Gq} / 11$ activation and calcium mobilisation in CHO cells. Eur $\mathrm{J}$ Pharmacol 594(1-3):32-8 
7. Chang CP, Chen SH, Lin MT (2005) Ipsapirone and ketanserin protects against circulatory shock, intracranial hypertension, and cerebral ischemia during heatstroke. Shock 24(4):33640

8. Newman-Tancredi A et al (2002) Differential actions of antiparkinson agents at multiple classes of monoaminergic receptor. III. Agonist and antagonist properties at serotonin, 5-HT(1) and
5-HT(2), receptor subtypes. J Pharmacol Exp Ther 303(2):81522

9. Cox B, Kerwin R, Lee TF (1978) Dopamine receptors in the central thermoregulatory pathways of the rat. J Physiol 282:47183

10. Onofrj M, Thomas A (2005) Acute akinesia in Parkinson disease. Neurology 64(7):1162-9 